\title{
The acquisition by the fetus of bacterial infection in pregnancy and labour
}

\author{
PAMELA A. DAVIES \\ From the Department of Paediatrics and Neonatal Medicine, Hammersmith Hospital, London
}

At the beginning of this century the recovery of typhoid bacilli was reported from the tissues of 10 out of 30 fetuses, all of whose mothers had contracted the disease at varying stages in pregnancy (Hicks and French, 1905). This was by no means the first demonstration that maternal bacterial infection could be transmitted to the unborn child, but the report was important for two reasons. First, it showed that placental transfer of bacterial agglutinins occurred, for an uninfected fetus was found to have a positive Widal reaction. Such transfer had been recorded previously only for the virus infections of measles and variola and for syphilis. Second, it also showed that fetal infection was to some extent dependent on the duration of maternal infection. In the intervening years bacterial infection has become less flamboyant-due to improving social and economic circumstances as much as to the advent of antibacterial drugs-but it seems likely that its subtleties where the fetus and newborn are concerned are as yet only half understood. This paper will seek to review the development of defence mechanisms of the fetus and some of the ways in which the child may be compromised if and when these defences are breached.

Several comprehensive recent reviews outline the main events in the immunological calendar of the fetus (Gotoff, 1974; Stiehm, 1975). At about eight weeks of gestation, stem cells from liver or spleen migrate to the thymus to become the origins of the cellular immune or $\mathrm{T}$ cell system. After maturation, they leave the thymus to concentrate particularly in lymph nodes and spleen. Development of the antibody or B cell system starts with the synthesis of IgM, mainly in the spleen, at about 11 weeks, IgG synthesis begins a week or so later, whereas formation of IgA does not occur until 30 weeks' gestation. In the absence of antigenic stimulus during intrauterine life levels of $\operatorname{IgA}$ and IgM are very low at birth. Active transfer of IgG, the only one of the immune globulins to cross the placenta, takes place largely in the last trimester, so that cord blood levels of IgG equal or exceed those of the mother in the mature infant. Phagocyte and macrophage precursors are present in the liver at eight weeks of intrauterine life, at which time the complement system also starts to form. The individual components of complement and its activity increase steadily throughout gestation, but at birth levels are only $50 \%$ those of adult values. This relative deficiency, together with that of IgM antibodies at birth, is probably mainly responsible for the impaired opsonic activity and hence relative inefficiency of phagocytosis where Gram-negative bacteria are concerned.

In the past contradictory views have been put forward on the ability or otherwise of amniotic fluid to suppress bacterial growth. Recent work (Larsen et al, 1974a and b; Schlievert et al, 1975a and b) suggests that it does indeed fail to support growth, at least of certain bacteria; that this bactericidal effect is directly related to its concentration and to gestational age; and that this property is due to the presence in it of a specific inhibitor. As others have pointed out (Smith and Eitzman, 1964), nature equips the infant with defence mechanisms that are appropriate for the challenges likely to be met at various stages of existence. Nevertheless preterm birth is an accident which finds the infant ill prepared for bacterial onslaught. There is also evidence accumulating to show that intrauterine growth retardation may be associated with an immune defect persisting into the first year of life (Chandra, 1974).

Acute obvious bacterial infection in a pregnant woman is today likely to be treated promptly with antibiotic drugs, and it may well be that unrecognized or chronic maternal bacterial infection is more harmful to the fetus. Bacteriuria may be found in 5 to $8 \%$ of pregnant women depending on age, parity and social class (Kass and Zinner, 1973). An excess of low birth weight infants born to such bacteriuric mothers has been reported (Kass, 1962), and, though this remains a controversial topic, antibiotic therapy to sterilize the urine is believed to reverse this trend. The known relationship between low socioeconomic status and an increased incidence of bacteriuria, and between low socioeconomic status, low birth weight and increased perinatal mortality makes large numbers essential for discrimination of 
these variables. Intrauterine infection is always suspected if the cord IgM level is above $20 \% \mathrm{mg}$. The frequency with which this occurs varies enormously in different populations. For instance, in middle income consecutive births it may be as low as $0.2 \%$ (Stiehm, 1975) whereas in the low income rural population of a developing country it may be as high as $49 \%$ (Lechtig and Mata, 1970, 1971). There is general agreement that in a sizeable proportion of newborn infants with raised cord blood IgM levels no diagnosis as to cause is made. Whereas it is now possible to exclude with fair precision on serological and/or cultural grounds many viral, protozoal and spirochaetal infections, newer techniques for diagnosis of past bacterial infection are not yet generally available, and, at the best, presumptive diagnosis may be made merely by exclusion. The possibility that prenatal bacterial infection may be harmful to developing brain in the same way as viral infections seems a real one. For instance titres of Listeria antibodies were found to be significantly higher among a group of mentally retarded children in whom previous investigation had revealed no likely cause when compared with similarly retarded children of certain aetiology (Lang, 1955). Individual cases showing obvious structural damage of the brain, such as that reported by Crosby et al (1951) in which intrauterine meningtitis due to Staphylococcus aureus presented as hydrocephalus in utero, are the exception.

If it is difficult to give a quantitative estimate of the risk to the fetus during the first and second trimester of pregnancy, it is equally difficult to do so in the third trimester when ascending rather than transplacental infection becomes more likely as term approaches. The incidence of chorioamnionitis is higher than that of all perinatal morbidity and mortality together, and increases in incidence as the interval between membrane rupture and delivery, and with decreasing birth weight (Benirschke and Driscoll, 1967). Perinatal studies by Naeye and colleagues have demonstrated that about one-third of stillbirths and early neonatal deaths are associated with an infected intrauterine environment, as judged by its presence, and the proportion increases with low socioeconomic status, and a maternal history of previous unsuccessful pregnancies. These workers have found the adrenal glands heavier by $19 \%$ in infected cases, suggesting to them that adrenal hyperfunction might have been important in initiating premature labour (Naeye and Blanc, 1970, 1973; Naeye et al, 1971).

At Hammersmith Hospital over the past nine years, it has been a routine to perform blood cultures whenever neonatal infection is suspected and before antibacterial therapy is started. In addition blood has been withdrawn for culture immediately after any death in the neonatal period. Thus a serious search has been made for neonatal bacteraemia, and during the period 1967-1975 inclusive 26 cases have occurred among 16240 live births at the hospital, a rate of $1 \cdot 6 / 1000$ live births. Beta-haemolytic streptococcus (Lancefield group B) was the commonest infecting organism $(0 \cdot 4 / 1000$ live births). One-third of infants in the neonatal intensive care unit at the hospital are referred from elsewhere in the first few days of life because of illness and/or very low birth weight. During the same time period positive blood cultures occurred at a rate of $75 \cdot 9 / 1000$ admissions among this highly selected newborn population. The distribution of positive cultures among all infants, inborn and outborn, is shown in the table, the figures for inborn infants being given in parentheses. Without prospective study of the bacterial flora of mother and child it is not possible to say to what extent maternally derived organisms were the cause of neonatal illness. A recent survey in this unit (Graham, 1975) with serotyping of Escherichia coli and pyocine typing of Pseudomonas aeruginosa suggested that many low birth weight infants acquire their organisms from the environment, and this source seems likely for practically all cases of bacteraemia due to the latter organism, and probably the majority of those caused by the Klebsiella-Enterobacter-Serratia species. On the other hand, the single case of Listeria monocytogenes bacteraemia was shown to be maternally transmitted, and in several recent cases of group B streptococcus bacteraemia the same types (usually Ia and II) have been recovered from the maternal vagina.

Analysis of the neonatal course of the infants revealed that those with streptococcal disease formed a well defined group, with an illness of very early onset, in the great majority within 12 hours of birth.

\begin{tabular}{ll}
\hline Bacteria & Number of Isolates \\
\hline Aerobes & \\
Escherichia coli & $20(4)^{1}$ \\
Pseudomonas aeruginosa & $18(4)$ \\
Group B streptococcus & $16(7)$ \\
Klebsiella-Enterobacter-Serratia species & $13(1)$ \\
Staphylococcus albus & $6(5)$ \\
Staphylococcus aureus & $3(1)$ \\
Streptococcus faecalis & $2(1)$ \\
Streptococcus viridans & 1 \\
Listeria monocytogenes & $1(1)$ \\
Haemophilus influenzae & $1(1)$ \\
Achromobacter & $1(1)$ \\
Mixed & 6 \\
Anaerobes & 1 \\
Bacteroides & 1 \\
Clostridium perfringens & 1 \\
Mixed Aerobes and Anaerobes &
\end{tabular}

Table Distribution of isolates from positive blood cultures made during life or immediately after death in the neonatal period

${ }^{1}$ Figures in parentheses indicate infants born in Hammersmith Hospital, 1967-1975, and are included in the totals. 
As others have described (Franciosi et al, 1973), respiratory distress, recurrent apnoea and alarmingly quick deterioration with shock characterize the clinical picture, and mortality is high. Surgical induction of labour had been carried out in a high proportion of cases. In a survey of the microbial flora of the lower genital tract during pregnancy de Louvois et al (1975) recently isolated group B streptococci from $5 \cdot 5 \%$ of patients at their first antenatal visit to a London maternity hospital. Using a selective broth medium Baker and Barrett (1975) were able to show an isolation rate of $25.4 \%$ from women admitted in labour, and pointed out that $58.7 \%$ of the isolates would have been missed if the selective medium had not been used, because of the overgrowth of Gram-negative organisms. Thus, they were able to show that group B streptococcal colonization among mothers was $254 / 1000$, and among infants $262 / 1000$, with an attack rate for proved neonatal infection of $2 \cdot 9 / 1000$. They also believe that isolation of the organism from mothers increases with advancing gestational age (Baker et al, 1975). Mathews and his coworkers (1974) have found that only $10 \%$ of the population have an opsonizing antibody to the type Ia group B streptococcus, and this might explain its exceptionally high mortality in the neonatal period. The binding of complement by the antibody greatly enhanced the degree of opsonization. These workers believed that the exclusive isolation of type IIIb streptococcus in meningitis suggested that infection and subsequent killing of this organism by polymorphonuclear leucocytes might differ from that of the other serotypes. It seems likely that cases of streptococcal bacteraemia may be easily missed by paediatricians and even pathologists unless blood cultures are made as a routine in ill babies. The disease can masquerade convincingly as respiratory distress syndrome, even to characteristic radiological findings, and hyaline membranes at necropsy. The latter are patchy rather than uniform in distribution, however, and the cocci may be unevenly distributed in them; atelectasis is minimal. The cocci may be seen on smears of gastric aspirate (Ablow et al, 1976).

There is as yet no convincing evidence that treatment of colonized mothers would result in disappearance of the organism, though there has naturally been discussion about the desirability of identifying carriers before delivery. Similarly there seems no good reason to treat colonized well babies. The tendency to planned delivery and hence surgical induction does mean that organisms could be introduced into the amniotic sac of more women than previously and a greater awareness among obstetricians and paediatricians of the possibility of early neonatal infection seems essential.
I am most grateful to Drs Ruth Mitchison, Ann Uttley and Heather Jeffery for their help in compiling the authenticated cases of neonatal bacteraemia.

\section{References}

Ablow, R. C., Driscoll, S. G., Effmann, E. L., Gross, I., Jolles, C. J., Uauy, R., and Warshaw, J. B. (1976). A comparison of early-onset Group B streptococcal neonatal infection and the respiratory-distress syndrome of the newborn. New Engl. J. Med., 294, 65-70.

Baker, C. J., and Barrett, F. F. (1973). Transmission of Group B streptococci among parturient women and their neonates. J. Pediat., 83, 919-925.

Baker, C. J., Barrett, F. F., and Yow, M. D. (1975). The influence of advancing gestation on group B streptococcal colonization in pregnant women. Amer. J. Obstet. Gynec., 122, 820-823.

Benirschke, K., and Driscoll, S. G. (1967). The Pathology of the Human Placenta. Springer: Berlin and New York.

Chandra, R. K. (1974). Immunocompetence in low-birthweight infants after intrauterine malnutrition. (Letter). Lancet, 2, 1393-1394.

Crosby, R. M. N., Mosberg, W. H., Jr., and Smith, G. W. (1951). Intrauterine meningitis as a cause of hydrocephalus. J. Pediat., 39, 94-101.

de Louvois, J., Hurley, R., and Stanley, V. C. (1975). Microbial flora of the lower genital tract during pregnancy: Relationship to morbidity. J. clin. Path., 28, 731-735.

Franciosi, R. A., Knostman, J. D., and Zimmerman, R. A. (1973). Group B streptococcal neonatal and infant infections. J. Pediat., 82, 707-718.

Gotoff, S. P. (1974). Neonatal immunity. J. Pediat., 85, 149154.

Graham, J. M. (1975). An investigation into the aerobic and anaerobic baterial flora of normal and ill/low birthweight newborn babies. PhD Thesis, University of London.

Hicks, H. T., and French, H. (1905). Typhoid fever and pregnancy, with special reference to foetal infection. Lancet, 1 , 1491-1493.

Kass, E. H. (1962). Pyelonephritis and bacteriuria: a major problem in preventive medicine. Ann. intern. Med., 56, 4653.

Kass, E. H., and Zinner, S. H. (1973). Bacteriuria and pyelonephritis in pregnancy. In Obstetric and Perinatal Infections, edited by D. Charles and M. Finland, pp. 407446. Lea and Febiger: Philadelphia.

Lang, K. (1955). Listeria-Infektion als mögliche Ursache früh erworbener Cerebralschäden. Z. Kinderheilk., 76, 328339.

Larsen, B., Snyder, I. S., and Galask, R. P. (1974a). Bacterial growth inhibition by amniotic fluid. I. In vitro evidence for bacterial growth-inhibiting activity. Amer. J. Obstet. Gynec., 119, 492-496.

Larsen, B., Snyder, I. S., and Galask, R. P. (1974b). Bacterial growth inhibition by amniotic fluid. II. Reversal of amniotic fluid bacterial growth by addition of a chemically defined medium. Amer. J. Obstet. Gynec., 119, 497-501.

Lechtig, A., and Mata, L. J. (1970). Immunoglobulin levels in cord blood of Guatemalan village children. (Abstr.) Fed. Proc., 29, 578.

Lechtig, A., and Mata, L. J. (1971). Cord IgM levels in Latin American neonates. J. Pediat., 78, 909-910.

Mathews, J. H., Klesius, P. H., and Zimmerman, R. A. (1974). Opsonin system of the group B streptococcus. Infect. and Immun., 10, 1315-1320.

Naeye, R. L., and Blanc, W. A. (1970). Relation of poverty and race to antenatal infection. New Engl. J. Med., 283, 555-560. 
Naeye, R. L., and Blanc, W. A. (1973). Unfavourable outcome of pregnancy: repeated losses. Amer. J. Obstet. Gynec., 116, 1133-1137.

Naeye, R. L., Dellinger, W. S., and Blanc, W. A. (1971). Fetal and maternal features of antenatal bacterial infections. J. Pediat., 79, 733-739.

Schlievert, P., Larsen, B., Johnson, W., and Galask, R. P. (1975a). Bacterial growth inhibition by amniotic fluid. III. Demonstration of the variability of bacterial growth inhibition by amniotic fluid with a new plate-count technique. Amer.J. Obstet. Gynec., 122, 809-813.
Schlievert, P., Larsen, B., Johnson, W., and Galask, R. P. (1975b). Bacterial growth inhibition by amniotic fluid. IV. Studies on the nature of bacterial inhibition with the use of plate-count determinations. Amer. J. Obstet. Gynec., 122, 814-819.

Smith, R. T., and Eitzman, D. V. (1964). The development of the immune response: characterization of the response of the human infant and adult to immunization with Salmonella vaccines. Pediatrics, 33, 163-183.

Stiehm, E. R. (1975). Fetal defense mechanisms. Amer. J. Dis. Child., 129, 438-443. 